\title{
G6PD Deficiency in Two Autochthonous Croatian Families
}

\author{
DOROTEA JURIČIĆ, VLASTA VINCE-RIBARIĆ, IBRAHIM RUŽDIĆ, \\ and SILVIJE VULETIĆ
}

From the Research Department of Medical Biochemistry, Dr. O. Novosel Hospital; the Institute of Public Health of Croatia; and Andrija Stampar School of Public Health, Medical Faculty, University of Zagreb, Zagreb, Yugoslavia

In Europe G6PD deficiency is encountered most frequently in Sardinia and Greece but may also be found in other Mediterranean countries (Sansone, Piga, and Segni, 1958; Szeinberg, Asher, and Sheba, 1958), including Yugoslavia (Fraser, Grünwald, and Stamatoyannopoulos, 1966). The occurrence of haemolytic anaemia after ingestion of fava beans in Yugoslavia was first reported as a clinical finding by Vince-Ribaric in 1962 . The patients belonged to two autochthonous Croatian families from the vicinity of the town of Zadar on the Adriatic Coast. In the present study a full account is given of all the data obtained in the patients and their families.

\section{Material and Methods}

G6PD activity was determined in the two affected families: Family D and Family B-71 subjects in all. Blood samples were collected in vacuum containers* containing one drop of heparin. The blood was collected in the same way and under the same conditions from a control group comprising 27 patients and the staff of an orthopaedic hospital whose laboratory and anamnestic data ruled out the existence of haemolytic disease. The blood samples were collected over a period of 8 days, were kept at $+4^{\circ} \mathrm{C}$., and were transported by bus to the laboratory $300 \mathrm{~km}$. away.

Determination of G6PD activity in erythocytes was based on the Kornberg-Horecker method (Kornberg and Horecker, 1955) modified by Zinkham (Zinkham, 1959). G6PD activity was expressed in units per $100 \mathrm{ml}$. erythrocytes, one unit corresponding to the degree of activity causing reduction of $1 \mu$ mole NADP/1 min. in $3 \mathrm{ml}$. of the reaction mixture at $p \mathrm{H} 8$. The measurements were carried out at $28^{\circ} \mathrm{C}$. As clinical manifestations of favism vary considerably (Sansone et al., 1958), the classification recommended by Manai (Manai, 1929) was used for the presentation of clinical data.

Received March 6, 1969.

$\star$ (Vacutainer No. 3200, Becton, Dickinson and Co., Columbus, Nebraska; Rutherford, New Jersey, U.S.A.).

4

\section{Results}

The distribution of the activity was bimodal (Table and Fig. 1).

The subjects fell into one of 3 groups depending upon the level of G6PD activity. Group I comprised family members in whom the G6PD was very low, varying from 2-19 units per $100 \mathrm{ml}$. erythrocytes, and these were considered to be totally

TABLE

G6PD ASSAY: ENZYME LEVELS IN VARIOUS GENOTYPES

\begin{tabular}{|c|c|c|c|c|}
\hline \multirow[b]{2}{*}{$\begin{array}{l}\text { G6PD Units } / 100 \mathrm{ml} \text {. } \\
\text { Red Blood Cells }\end{array}$} & \multicolumn{2}{|c|}{ Males } & \multicolumn{2}{|c|}{ Females } \\
\hline & Normal & $\begin{array}{l}\text { Hemi- } \\
\text { zygotes } \\
\text { G6PD }\end{array}$ & Normal & $\begin{array}{l}\text { Hetero- } \\
\text { zygotes } \\
\text { G6PD }\end{array}$ \\
\hline $\begin{array}{c}0 \\
1-2 \\
3-4 \\
5-6 \\
7-8 \\
9-10 \\
11-12 \\
13-14 \\
15-16 \\
17-18 \\
19-20 \\
70-79 \\
80-89 \\
90-99 \\
100-109 \\
110-119 \\
120-129 \\
130-139 \\
140-149 \\
150-159 \\
160-169 \\
170-179 \\
180-189 \\
190-199 \\
200-209 \\
210-219 \\
220-229 \\
230-239 \\
240-249\end{array}$ & $\begin{array}{r}3 \\
2 \\
11 \\
8 \\
3 \\
3 \\
1 \\
- \\
1\end{array}$ & $\begin{array}{c}1 \\
1 \\
1 \\
1 \\
2 \\
1 \\
\frac{1}{1} \\
1\end{array}$ & $\begin{array}{l}3 \\
4 \\
5 \\
2 \\
5 \\
1\end{array}$ & $\begin{array}{l}1 \\
1 \\
2 \\
1 \\
2 \\
4 \\
2\end{array}$ \\
\hline $\begin{array}{l}\text { Total number of cases } \\
\text { Mean G6PD } \\
\text { SD } \\
\text { G6PD, \% of normal mean }\end{array}$ & $\begin{array}{l}32 \\
173 \cdot 13 \\
18 \cdot 38 \\
100\end{array}$ & $\begin{array}{c}9 \\
9 \cdot 56 \\
5 \cdot 50 \\
5 \cdot 52\end{array}$ & $\begin{array}{c}20 \\
166 \cdot 30 \\
16 \cdot 58 \\
100\end{array}$ & $\begin{array}{c}13 \\
111 \cdot 90 \\
19 \cdot 31 \\
71 \cdot 56\end{array}$ \\
\hline
\end{tabular}




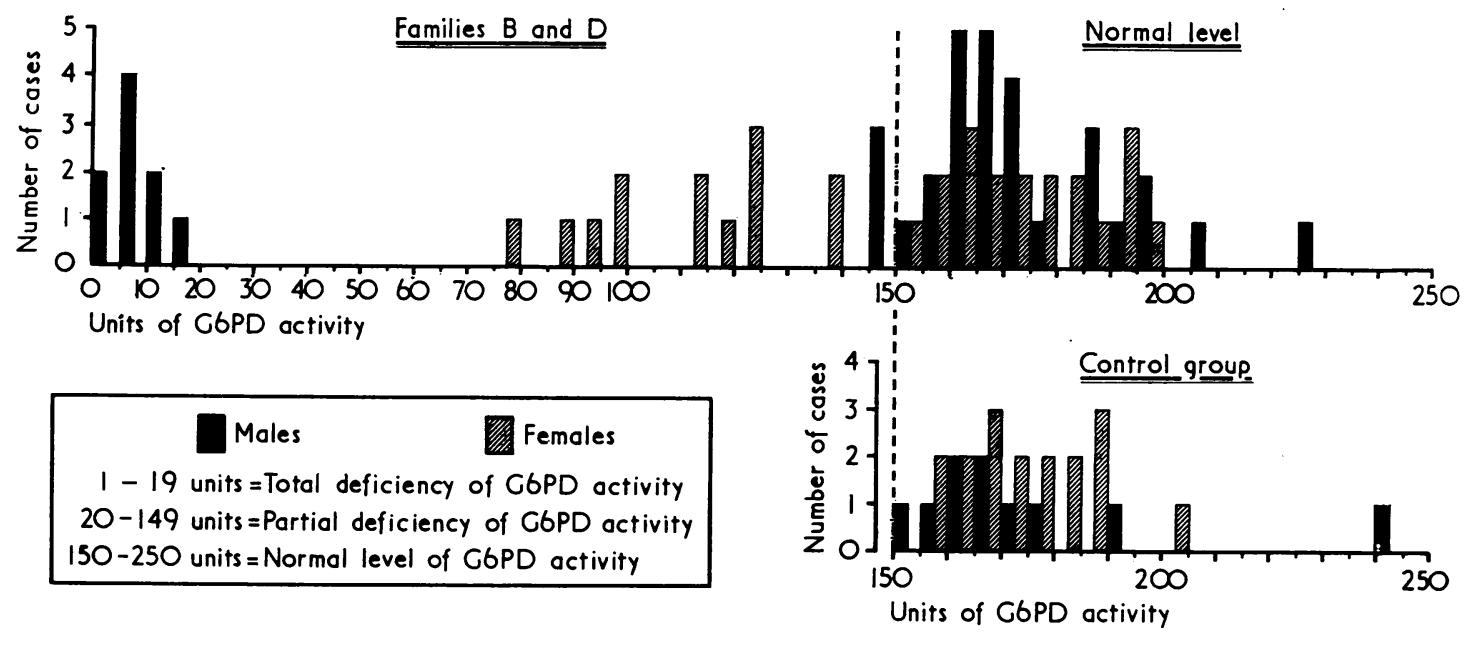

FIG. 1. Distribution of G6PD values in members of families $B$ and $D$.

deficient. Group II comprised subjects with G6PD activity ranging from 77 to 149 units, and these were considered to be partially deficient. Group III comprised members in whom the degree of activity was within the limits found in the control group, which had activities varying from 150 to 240 units.

Group I with 'total deficiency' consisted entirely of males, and clearly distinguished itself from Group II with partial deficiency, which consisted entirely of females. The latter group, however, did not clearly differ from Group III consisting of the family members with normal G6PD activity; in fact, these two groups overlapped. Three male members (B: III.6, III.7, and D: II.9) were on the boundary between Group I and Group II. However, these deviations were within the experimental error of the method.

Family D. Fig. 2 shows G6PD values in the members of Family D. The probands in this family were two boys aged 6 (III.9) and 3 years (III.10), respectively. They had total G6PD deficiency, and their clinical picture showed a severe icterohaemoglobinuric form causing serious general disorder and even unconsciousness. The mother of these two probands (II.7) had partial deficiency, while their father (II.8) had normal levels of G6PD. They had three other brothers: one was totally deficient (III.7), one was normal (III.8), and one was not examined (III.11). According to anamnestic data, the proband III.9 had had a very severe isolated haemolytic crisis which had never recurred, whereas his brothers (III.7 and III.10) had had several crises but of a milder form than $\frac{\mathbb{D}}{0}$ that suffered by the first proband (III.9). Haemo- $\mathbb{\mathbb { D }}$ lysis always developed after ingestion of fava beans $\frac{3}{0}$ or inhalation of their pollen. After the first attack $\stackrel{\mathbb{Q}}{\stackrel{2}{-}}$ the proband III.9 stopped eating broad beans but $\vec{\varphi}$ could not avoid contact with the pollen.

One uncle of the probands on their mother's sick (II.4) also had total G6PD deficiency. Married a woman (II.5) who was not examined, he had three daughters and one son. Two daughters (III.4 and III.5) had partial deficiency, while the third (III.3) had normal G6PD levels. It was not possible to $\stackrel{\varrho}{\rightleftharpoons}$ examine the son (III.6), nor was it possible to ex-을 amine another uncle of the probands (II.1) or his wife (II.2). On the basis of heteroanamnesis, the latter uncle must have had a haemolytic crisis in his childhood. From his marriage there were two daughters with partial deficiency (III.1 and III.2). In the uncle (II.9) on the father's side, the G6PD 3 . activity amounted to 148 units. This finding was considered normal, being within the experimental error of the method. He had a normal daughtero (III.12) whose G6PD activity was 184 units. The probands' aunt on their father's side (II.12), who, like her husband (II.13), was not examined, had a N daughter (III.13) with partial G6PD deficiency. O The probands' grandmother on their mother's side 0 (I.2) also had partial deficiency, while their grand- N father (I.1) had normal enzyme levels. Analysis of the genealogy of the probands' grandmother re-co vealed no member with G6PD deficiency.

Family B. Fig. 3 shows the occurrence of the 7 G6PD levels in the members of Family B. In this 

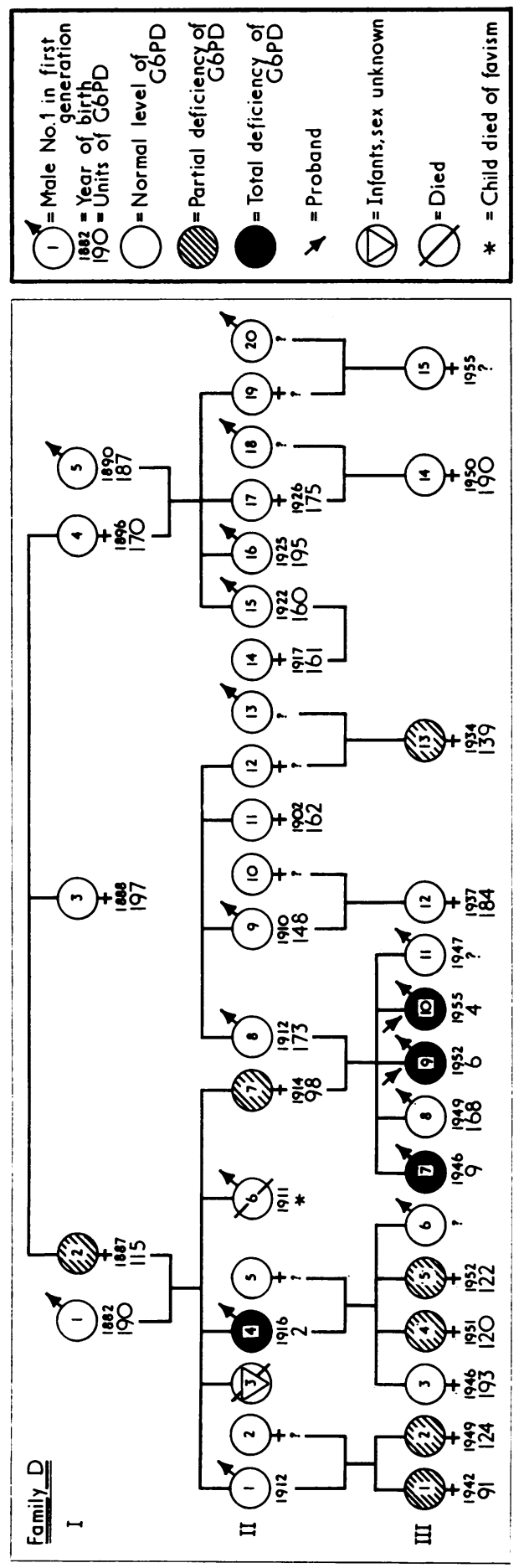

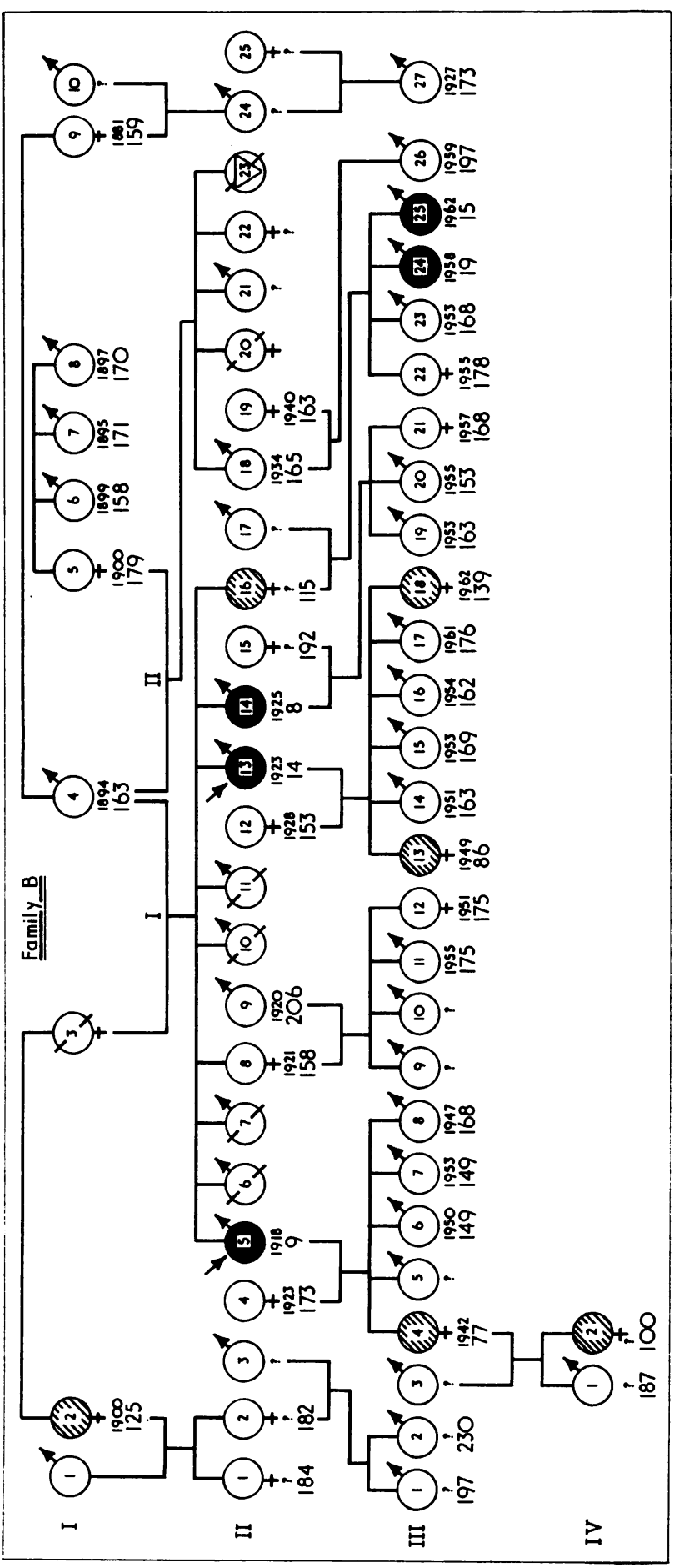

즐

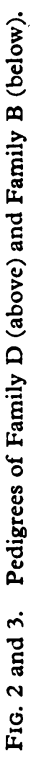


family the probands were a 40-year-old man (II.5) and his 35-year-old brother (II.13). They came to hospital with the clinical picture of a moderately severe icterohaemoglobinuric form of favism, with total G6PD deficiency. Their mother (I.3) was dead, and their father (I.4) had normal G6PD activity. The mother's sister (I.2) had partial G6PD deficiency. The probands had one more brother (II.14) with a total deficiency, and a sister (II.16) with partial G6PD deficiency, while one sister (II.8) was normal. The older proband (II.5), married to a healthy woman (II.4), had five children: out of his four sons, three had normal enzyme activity (III.6, III.7, and III.8); the fourth one (III.5) was not examined. The daughter (III.4) had partial G6PD deficiency, her son, however (IV.1), was healthy, and her daughter (IV.2) had partial G6PD deficiency. The younger proband (II.13) with total deficiency married a woman (II.12) with normal enzyme values, had two daughters (III.13 and III.18) with partial deficiency, and four sons (III.14, III.15, III.16, and III.17) with normal G6PD activity. One brother of the probands (II.14) with total deficiency was married to a healthy woman (II.15) and had three children (III.19, III.20, and III.21) with normal G6PD values. The probands' sister (II.16) with partial deficiency was married to a man (II.17) who was not examined; two of their sons (III.24 and III.25) had total G6PD deficiency, while the third son (III.23) and a daughter (III.22) had normal enzyme levels.

By comparing the family data with data on the degree of the G6PD activity in the patients' erythrocytes, it can be seen that Family B members (II.5, II.13, and II.14), with total G6PD deficiency, developed, when in contact with broad beans, a pronounced icterohaemoglobinuric form of favism, coupled with signs of general disorders, headache, and vertigo. Headache was particularly pronounced in II.14 who repeatedly, probably due to the inhalation of broad bean pollen, developed a form of favism not requiring hospital treatment.

The members of both families with partial deficiency suffered from headache, and weakness was particularly pronounced in spring. In addition, some members of Family D (III.14 and III.15) developed allergic reactions after taking certain kinds of food. One child of II.14 and II.15, of Family D, died during an attack of bronchial asthma. Another member of Family D (II.7) developed severe headache when in contact with certain plants from the family Crucifera.

A general observation made in these two families was that most members with partial deficiency and also some with normal G6PD activity did not like fava beans as food. This aversion was not ob- $\unrhd$ served in the control group. Nor was any trouble $\Phi$ reported in either affected or non-affected subjects after administration of any drug whatsoever.

\section{Discussion}

The occurrence of G6PD deficiency in these two families clearly corresponds to the $\mathrm{X}$ chromosome recessive hereditary type.

Two results obtained in this study do not, however, fit into the picture of the $\mathrm{X}$ chromosome hereditary pattern. The female member from Family B (III.21) is a daughter of one member with total deficiency (II.14), and cannot be a normal homozygote but must be a carrier of the pathological gene showing, consequently, partial G6PD deficiency. It could, however, be assumed that $i_{\infty}$ this finding is in favour of the Lyon hypothesis of a partial or total inactivity of one $\mathbf{X}$ chromosome, which results in the activity of only one allele (Lehmann and Huntsman, 1966; Lyon, 1961), so that a phenotype variability between heterozygotes can be expected. The same relates to the G6PD activity found in III.3, daughter of Family D member II.4 with total G6PD deficiency.

Cases of favism in Family B occurred in adufg persons. None of them, or their parents, couli remember suffering any trouble after contact with. fava beans in childhood. Two members of this family, III.24 and III.25, were children of 7 and 5 years of age who had 'total G6PD deficiency', but, until then, had had no trouble either after eating fava beans or after being exposed to the pollen.

However, in Family D, III.9, III.10, and III.7 developed clinical manifestations of favism only in childhood. According to anamnestic data, a child from this family (II.6) was said to have developed severe clinical manifestations of favism and died in his 6 th year during a haemolytic crisis. His brother (II.4), aged 52, had total G6PD deficiency-but even in contact with fava beans, he had never felt any discomfort.

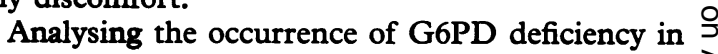
the two families described, one gets the impression $\frac{7}{0}$ that the mere presence of the pathological G6PD gene and the consumption of fava beans are not $N$ enough for the production of clinical signs of the $N$ disease, and that some other factors are likely to contribute. For instance, in Family B, two children with total G6PD deficiency (III.24 and III.25), though consuming fava beans, had never developed any symptoms. Perhaps age plays an important part in the appearance of the disease. Anyway, the situation appears far more complex than was con- 
sidered at the time when the genetic origin of the disease was discovered, and in addition to strictly hereditary factors, some other, so far unknown, environmental factors should probably be taken into account.

\section{Summary}

G6PD activity was analysed in two autochthonous Croatian families whose members developed haemolytic anaemia after ingestion of fava beans. The study embraced 71 members of these two families. The control group consisted of 27 persons.

G6PD activity in 9 male members ranged from 2 to 19 units, and in 13 female members from 77 to 140 units; in the remaining members it was within the limits observed in controls, in whom the range was from 150 to 240 units.

The relevant clinical and genetic data are presented and discussed.

We wish to thank Dr. J. Padelin, Director of the Medical Centre, Zadar, and Assistant Prof. S. Perović from the same Centre, and Dr. I. Radman from the Orthopaedic Hospital in Biograd for facilities to carry out this study in their area.

\section{REFERENCES}

Fraser, G. R., Grünwald, P., and Stamatoyannopoulos, G. (1966). Glucose-6-phosphate dehydrogenase (G-6-PD) deficiency, abnormal haemoglobins and thalassaemia in Yugoslavia. $\mathcal{f}$. med. Genet., 3, 35.

Kornberg, A., and Horecker, B. L. (1955). Glucose-6-phosphate dehydrogenase. In Methods in Enzymology, Vol. 1, p. 323. Ed. by S. P. Colowick and N. O. Kaplan. Academic Press, New York.

Lehmann, H., and Huntsman, R. G. (1966). Man's Haemoglobins, Chapter 16, p. 188. North-Holland Publishing Co., Amsterdam.

Lyon, M. F. (1961). Gene action in the X-chromosome of the mouse (mus musculus L.). Nature (Lond.), 190, 372.

Manai, A. (1929). Il Favismo. Stamparia Libr. Ital. Stran. (cited in Sansone et al. (1958)).

Sansone, G., Piga, A. M., and Segni, G. (1958). Il Favismo. Minerva Medico, Torina.

Szeinberg, A., Asher, Y., and Sheba, C. (1958). Studies on Glutathione stability in erythrocytes of cases with past history of favism or sulfa-drug-induced hemolysis. Blood, 13, 348.

Vince-Ribarić, V. (1962). Klinički prilog upoznavanju favizma (Clinical contribution to the knowledge of favism). Liječn. Vjesn., 84, 151.

Zinkham, W. H. (1959). An in-vitro abnormality of glutathione metabolism in erythrocytes from normal newborns: Mechanism and clinical significance. Pediatrics, 23, 18. 